\title{
Development and Validation of a Discriminatory Dissolution Testing Method for Orally Disintegrating Tablets (ODTs) of Domperidone
}

Amjad Khan

Department of Pharmacy, Abasyn University, Peshawar-25120, Pakistan e-mail: amjadph@gmail.com

\begin{abstract}
The orally disintegrating tablet (ODT) is a novel dosage form that disintegrates in the oral cavity using saliva as the disintegrating medium and is swallowed as a fine dispersion. Due to rapid disintegration, the dissolution rate is controlled by the intrinsic solubility of the API; therefore, it is difficult to evaluate the effect of formulation and processing parameters on in vitro drug release. Thus, a dissolution method that can discriminate among in vitro release profiles of ODTs with varying natures is needed. The objective of the present study was to develop and validate a discriminative dissolution testing method for ODTs of domperidone. Different experimental conditions such as dissolution medium composition, dissolution medium volume, and paddle rotation speed were evaluated. Analysis of dissolution samples was carried out by HPLC using a combination of water at $\mathrm{pH} 3$ and acetonitrile $(65: 35 \mathrm{v} / \mathrm{v})$ as the mobile phase. The developed dissolution method was validated according to $\mathrm{ICH}$ guidelines for various parameters such as specificity, accuracy, precision, and stability. The discriminatory nature of the method was confirmed by determining the dissolution rate of ODTs containing pulverized and unpulverized domperidone. The best in vitro dissolution profile was obtained using purified water containing $1 \%$ Tween 80 as the dissolution medium $(900 \mathrm{~mL})$ stirred at $50 \mathrm{rpm}$. Complete dissolution $(100.09 \pm 0.37 \%)$ was achieved within $60 \mathrm{~min}$, and the dissolution medium did not interfere with sample analysis. All the validation parameters were in an acceptable range (RSD $>2 \%$ ). A comparison of the dissolution profiles in official and developed media showed significant differences based on $f_{1}$ and $f_{2}$ values. The developed dissolution test exhibited a higher capacity than the compendial methods in differentiating the release profiles of ODTs. It can be applied during formulation development and quality control analysis of ODTs for evaluation of the effects of formulation and processing parameters.
\end{abstract}

KEYWORDS: Domperidone; discriminative dissolution method; ICH Guidelines; validation.

\section{INTRODUCTION}

T 0 produce its effect, a drug must be released from a dosage form and should be made available for absorption in gastrointestinal fluids (1-3). Dissolution testing is considered a surrogate for the assessment of bioavailability because it determines drug release from the dosage form and predicts its absorption from gastrointestinal tract (4).

Dissolution testing has been a key tool during drug development stages and in the commercial preparation of the dosage forms $(3,5)$. At the formulation development stage, dissolution testing is used to evaluate stability, monitor product consistency, and assess the effect of variables (e.g., changes in formulation and process parameters) on the characteristics of the final product (6). For commercial products, dissolution testing is used to confirm manufacturing and product consistency and to evaluate process variables (7). With the accumulation of both in vivo and in vitro experience during the product development cycle, the dissolution test method should be critically reevaluated and potentially simplified for final quality control testing. In dissolution test development, the process should focus on assessing relevant physical and chemical properties of the API and dosage form design, because these will guide the choice of the dissolution medium and apparatus $(4,8)$. For the purpose of dosage form development, APIs can be classified into the following:

- Intrinsic dissolution-limited absorption: The APIs have poor water solubility, and the resultant dosage forms have low dissolution rates. Various formulation approaches like particle size reduction, solid dispersions, and liqui-solid compacts are applied for enhancement of dissolution rate and subsequent bioavailability of the drug.

- Disintegration controlled absorption: The APIs have better solubility profiles, and the resultant dosage forms show higher dissolution rates. Dissolution rate of a drug can be enhanced by increasing its disintegration. 
Low-solubility drugs are usually lipophilic, and drug release is the rate-limiting process for oral drug absorption of these substances (9). The development of a meaningful dissolution procedure (one that can evaluate both product consistency and bioavailability) for drug products with limited water solubility has been a challenge to both the pharmaceutical industry and the agencies that regulate them.

The discriminatory power of the dissolution testing method is its ability to detect the effect of minor changes in process and formulation on dissolution rate $(10,11)$. Demonstration of the discriminatory power of a dissolution method is challenging and important, particularly in monitoring API or formulation parameters critical for optimal product performance of poorly soluble drugs.

The systematic development of a dissolution method of discriminatory nature is required at the earlier stages of product development because it enables the formulator to adopt the right approach in finalizing the prototype formula and process for further scale-up (11). In addition, demonstration of the discriminatory nature of the dissolution method to be used in routine quality control of commercial batches is expected by major regulatory agencies worldwide (12).

According to the European Pharmacopoeia (13), an ODT is defined as an "uncovered tablet for buccal cavity, where it disperses before ingestion." ODTs display fast and spontaneous disintegration in the oral cavity, using saliva as the disintegration medium. Orally disintegrating tablets are placed in the oral cavity, allowed to disperse in the saliva, and swallowed as fine dispersions, obviating the need for water during administration (14). Officially ODTs will disintegrate within $3 \mathrm{~min}$ (13), but in practice, the disintegration time is less than 1 min (15). ODTs are gaining importance due to better taste, palatability, ease of administration, and avoidance of the risk of suffocation. This novel dosage form is of prime importance for pediatric, geriatric, bed-ridden, noncompliant patients, and those with limited or restricted water intake (16-19). Due to smaller disintegration times, similar dissolution profiles are obtained for different ODT formulations containing APIs with intrinsic dissolution-dependent absorption (Class 2 drugs). Due to rapid disintegration, ODTs show a burst release during initial stages (up to 15 $\mathrm{min})$, masking the effect of variables on dissolution rate. There is a need for the development of a dissolution method that can discriminate among ODT formulations of varying nature and is capable of demonstrating the effect of minor changes on dissolution rate.
In the present study, a discriminative dissolution testing method was developed and validated for ODTs of domperidone (20). According to the Biopharmaceutics Classification System (BCS), domperidone is a Class 2 drug, having poor water solubility and higher permeability. It is available in 10-mg tablets (21) and is a $\mathrm{D}_{2}$ antagonist usually prescribed as an antiemetic agent (22). Domperidone has a molecular weight of $425.911 \mathrm{~g} / \mathrm{mol}$, a $\mathrm{p} k_{\mathrm{a}}$ value of 7.9 , and a melting point in the range of $244-246^{\circ} \mathrm{C}(23)$.

The official dissolution medium for domperidone tablets $(0.1 \mathrm{~N} \mathrm{HCl})$ is not suitable for a discriminating dissolution test to support product development process of ODTs. Hence the objective of the present study was to develop and validate a discriminating dissolution method for ODTs of domperidone to support product development efforts.

\section{EXPERIMENTAL}

\section{Material and Instruments}

Domperidone (purity 99.93\%; Ningbo Sansheng Pharmaceuticals Company, China) was gifted by Medicraft Pharmaceuticals, Peshawar, Pakistan. Acetonitrile, hydrochloric acid, and Tween 80 were purchased from the pharmaceutical market of Peshawar, Pakistan. All of the reagents were of analytical grade and were used as received. Purified water was prepared by a Milli-Q system (Millipore, Milford, MA, USA).

Dissolution studies were performed in PharmaTest dissolution testing apparatus (PharmaTest, Germany), and estimation of the drug content was carried out by high performance liquid chromatography. The HPLC system was equipped with an auto sampler, vacuum degasser, Peltier column oven, pump, and UV-vis detector (PerkinElmer Series 200 system, Norwalk, USA). The chromatographic data was analyzed with PerkinElmer Total-Chrom workstation software (version 6.3.1, USA) linked with the LC system through a network chromatography interface ( $\mathrm{NCl}) 900$. A Hypersil BDS C8 column $(150 \mathrm{~mm} \times 4.6 \mathrm{~mm}, 5 \mu \mathrm{m})$ was used as stationary phase and was protected by a Perkin Elmer precolumn guard cartridge C18 (30 mm × $4.6 \mathrm{~mm}, 10 \mu \mathrm{m}$; Norwalk, CT, USA).

\section{Determination of Equilibrium Solubility of Domperidone}

The flask-shake method was applied for the determination of the equilibrium solubility of domperidone in various solvents (24). An excess of drug was added to 50 $\mathrm{mL}$ of the test solvent, sonicated for $10 \mathrm{~min}$, and subjected to continuous shaking on a mechanical shaker (Morgan Instruments, Pakistan) for $24 \mathrm{hr}$ at ambient temperature. At the completion of the shaking period, the solution

Dissolution MAY 2017 Technologies 
was kept undisturbed for $1 \mathrm{hr}$ to achieve equilibrium, filtered (Whatman filter paper \#42; 2.5 - $\mu \mathrm{m}$ pore size), and analyzed for drug content using HPLC.

Saturation solubility of domperidone was determined in:

- $0.1 \mathrm{~N} \mathrm{HCl}$ (official dissolution medium)

- $0.1 \mathrm{~N} \mathrm{HCl}+$ Tween $80(1 \% \mathrm{w} / \mathrm{v})$

- Purified water

- Purified water + Tween $80(0.5 \% \mathrm{w} / \mathrm{v})$

- Purified water + Tween $80(1 \% \mathrm{w} / \mathrm{v})$

- Purified water + Tween $80(1.5 \% \mathrm{w} / \mathrm{v})$

- Phosphate buffer (pH 6.8)

- Phosphate buffer (pH 6.8) + Tween 80 (1\% w/v)

The domperidone content of each solution was determined in triplicate, and results are presented as mean \pm SD.

\section{Dissolution Rate Studies}

The dissolution rate of domperidone ODTs was determined using USP dissolution Apparatus 2 (paddle). One tablet was put into each flask of the dissolution testing apparatus containing dissolution medium at $37 \pm$ $2{ }^{\circ} \mathrm{C}$. Aliquots $(5 \mathrm{~mL})$ were withdrawn at specified time intervals $(0,5,10,15,30,45$, and $60 \mathrm{~min})$, filtered, and analyzed in triplicate by HPLC for the amount of drug released. The method of analysis was developed and validated in a previous study (25). After each sampling, the dissolution medium volume was corrected by addition of the same quantity of medium at the same temperature.

The recommended dissolution medium for domperidone is $0.1 \mathrm{~N} \mathrm{HCl}(900 \mathrm{~mL})$ at $37 \pm 2{ }^{\circ} \mathrm{C}$ and stirred at $50 \mathrm{rpm}$. In the present study, the two parameters of medium composition and variation in paddle speed were studied to produce discriminating results. The composition of the various dissolution media used in the study are:

- $0.1 \mathrm{~N} \mathrm{HCl}$

- Purified water

- Purified water $+0.5 \%$ Tween 80

- Purified water $+1 \%$ Tween 80

- Purified water $+1.5 \%$ Tween 80

The effect of paddle speed on the dissolution rate was studied at $50 \mathrm{rpm}$ ( $B P$ recommended speed) and $75 \mathrm{rpm}$ in all dissolution media.

\section{Determination of Domperidone Content of the Samples}

During dissolution testing, samples were collected at specified time intervals, and the domperidone content was determined by HPLC (25). A combination of acetonitrile and acidified water (35:65) was used as mobile phase at $40{ }^{\circ} \mathrm{C}$ and a flow rate of $1.5 \mathrm{~mL} / \mathrm{min}$. The detector wavelength was set at $210 \mathrm{~nm}$.

In addition to the officially recommended dissolution medium $(0.1 \mathrm{~N} \mathrm{HCl})$, purified water alone and with different concentrations of Tween $80(0.5,1.0$, and $1.5 \%$ $\mathrm{w} / \mathrm{v})$ were used as dissolution media.

\section{Preparation of Standard Stock Solution}

A stock solution of domperidone was prepared by dissolving drug in methanol to obtain a concentration of $0.5 \mathrm{mg} / \mathrm{mL}$. Working solutions were prepared on a daily basis by diluting aliquots from the stock solution with respective dissolution media. Each solution was filtered before analysis.

\section{Validation of the Dissolution Method}

The selected dissolution method was validated for various parameters such as specificity, accuracy, precision, and stability according to $\mathrm{ICH}$ guidelines.

\section{Specificity}

Specificity of the dissolution method was evaluated by examining the effect of each dissolution medium on the peak characteristics of area, height, retention time, and tailing factor. Each dissolution medium was evaluated without drug (blank) and with a known amount of drug, and the results were compared.

\section{Accuracy}

The percent recovery was used to determine the accuracy of the proposed dissolution method. A solution containing $10 \mathrm{mg} / \mathrm{mL}$ of domperidone was prepared in methanol. Aliquots $(0.8,1.0$, and $1.2 \mathrm{~mL})$ of the solution were added to the dissolution medium $(900 \mathrm{~mL})$ to obtain a drug concentration in the range of $80-120 \%$ of the nominal dose. The dissolution medium was kept at $37 \pm 2$ ${ }^{\circ} \mathrm{C}$ and stirred at $75 \mathrm{rpm}$ for $15 \mathrm{~min}$. Samples $(5 \mathrm{~mL})$ were withdrawn and analyzed for drug content. The percent recovery was calculated using following equation:

$$
\text { Percent Recovery }=A / B \times 100
$$

where $A$ is the peak area of the test solution and $B$ is the peak area of standard solution.

For each sample, percent recovery was calculated in triplicate, and results are presented in terms of mean, 
standard deviation, and relative standard deviation (mean \pm SD; RSD).

\section{Precision}

Precision of the method was determined in terms of repeatability and intermediate precision. For repeatability, the dissolution test was performed simultaneously in six dissolution vessels under the same conditions, and the results were compared for variability.

Intermediate precision was evaluated on the basis of intraday and interday studies. An intraday study was performed by repeating the dissolution test three times a day, and the results were compared. For the interday study, the dissolution test was repeated on daily basis for three days under the same conditions, and results were compared for variability. An RSD less than 5\% indicates precision of the method.

\section{Solution Stability}

Solution stability was determined at three temperatures $\left(2-8{ }^{\circ} \mathrm{C}, 24 \pm 3{ }^{\circ} \mathrm{C}\right.$, and $\left.40 \pm 3{ }^{\circ} \mathrm{C}\right)$ for seven days. A stock solution of domperidone was diluted with the respective dissolution media to $20 \mu \mathrm{g} / \mathrm{mL}$. Each solution was divided into three portions and stored at the specified temperatures for seven days. Samples were analyzed daily for domperidone content, and the percent recovery was calculated in triplicate. Results are presented as mean \pm SD and RSD.

\section{Comparison of Dissolution Profiles by Model-Independent Method}

A model-independent approach was applied for the comparison of dissolution profiles (27-29). The comparison of dissolution profiles was based on the similarity factor $\left(f_{2}\right)$ and dissimilarity factor $\left(f_{1}\right)$, calculated using following equations:

$$
\begin{gathered}
f_{2}=50 \cdot \log \left\{\left[1+\frac{1}{n} \sum_{t=1}^{n}\left(R_{t}-T_{t}\right)^{2}\right]^{-0.5} \times 100\right\}(2) \\
f_{1}=\left\{\left[\sum_{t=1}^{n}\left|R_{t}-T_{t}\right|\right] /\left[\sum_{t=1}^{n} R_{t}\right]\right\} \times 100
\end{gathered}
$$

where $R_{t}$ is the dissolution rate of standard product at time $t$, and $T_{t}$ is the dissolution rate of test product at time t.

An $f_{2}$ value of 50 or greater ensures sameness or equivalence of the two curves and also the performance of the two products.

\section{RESULTS AND DISCUSSION}

Domperidone is a Class 2 drug and is available as $10-\mathrm{mg}$ tablets. ODTs of domperidone were prepared containing $10 \mathrm{mg}$ of domperidone, croscarmellose sodium, microcrystalline cellulose (PH-112), magnesium stearate, polyethylene glycol (PEG-4000), and Tablettose 80. Tablets were compressed using oblong, shallow concave punches $(10 \mathrm{~mm})$ under a compression weight of 200 $\mathrm{mg} /$ tablet. A direct compression technique was applied for the preparation of ODTs. ODTs having the same composition (formulation) and prepared by the same process were used throughout the study. To confirm the discriminatory nature of the developed dissolution method, modifications were made in the characteristics of domperidone (particle size). The British Pharmacopeia (30) recommends $0.1 \mathrm{~N} \mathrm{HCl}$ as the medium for dissolution testing of domperidone at $50 \mathrm{rpm}$. The inability of the recommended dissolution testing method to discriminate among different formulations of ODTs is attributed to the higher solubility and lower $\mathrm{pH}$, which would mask the effect of variables on dissolution rate. So the objective of this study was the development and validation of a dissolution method for domperidone ODTs that could discriminate the dissolution profiles of tablets of varying nature.

Table 1. Equilibrium Solubility and Sink Conditions of Domperidone in Different Dissolution Media

\begin{tabular}{|c|c|c|}
\hline Dissolution Medium & Solubility $(\mu \mathrm{g} / \mathrm{mL})$ & $\mathrm{C}_{\mathrm{s}} / \mathrm{C}_{\mathrm{d}}$ \\
\hline Purified Water & $8.46 \pm 0.14$ & 0.85 \\
\hline $\begin{array}{c}\text { Purified Water }+0.5 \% \\
\text { Tween } 80\end{array}$ & $13.22 \pm 0.14$ & 1.32 \\
\hline $\begin{array}{c}\text { Purified Water + 1\% } \\
\text { Tween 80 }\end{array}$ & $21.62 \pm 0.21$ & 2.16 \\
\hline $\begin{array}{c}\text { Purified Water + 1.5\% } \\
\text { Tween 80 }\end{array}$ & $13.89 \pm 0.19$ & 1.39 \\
\hline $0.1 \mathrm{~N} \mathrm{HCl}$ & $298.61 \pm 0.27$ & 29.86 \\
\hline $\begin{array}{c}0.1 \mathrm{~N} \mathrm{HCl}+1 \% \text { Tween } \\
80\end{array}$ & $352.77 \pm 0.16$ & 35.28 \\
\hline $\begin{array}{c}\text { Phosphate Buffer (pH } \\
6.80)\end{array}$ & $2.09 \pm 0.13$ & 0.21 \\
\hline $\begin{array}{c}\text { Phosphate Buffer + } \\
1 \% \text { Tween } 80\end{array}$ & $2.18 \pm 0.20$ & 0.22 \\
\hline
\end{tabular}

Results are mean $\pm S D(n=3)$.

The data were rounded to two digits after decimal point.

\section{Equilibrium Solubility of Domperidone}

Solubility plays a prime role in the dissolution of a drug substance from a solid dosage form. Correlations between solubility and dissolution rate of different drug substances in various media are well-established. The results of the solubility study and the influence of sink 
conditions on domperidone are presented in Table $1 . \ln \mathrm{pH}$ 6.8 phosphate buffer, the solubility of domperidone was very low $(2.09 \pm 0.13 \mu \mathrm{g} / \mathrm{mL})$ and remained unaffected by addition of surfactant. According to the BCS, domperidone is Class 2, exhibiting pH-dependent solubility. It is highly soluble at lower $\mathrm{pH}(1-3)$ but precipitates at higher $\mathrm{pH}$ $(>6)$, and its release from the dosage form is inhibited (31). Higher solubility of domperidone was observed in $0.1 \mathrm{~N}$ $\mathrm{HCl}(298.61 \pm 0.27 \mu \mathrm{g} / \mathrm{mL})$, which was further enhanced by addition of Tween 80 (352.77 $\pm 0.16 \mu \mathrm{g} / \mathrm{mL})$. In comparison with $0.1 \mathrm{~N} \mathrm{HCl}$, the solubility of domperidone in water is very low $(8.46 \pm 0.14 \mu \mathrm{g} / \mathrm{mL})$ and is increased by the addition of surfactant (Tween 80 ). Tween 80 showed a concentration-dependent increase in solubility up to $1 \%$, and further increase in concentration had no significant effect, as shown in Table 1.

The nominal dose of domperidone is $10 \mathrm{mg} /$ tablet, and the ratio of solubility to the dose $\left(C_{s} / C_{d}\right)$ was used for the prediction of sink conditions. Sink conditions occurs when the amount of drug that can be dissolved in the dissolution medium is three times greater than the amount of drug to be dissolved (32). A low $C_{s} / C_{d}$ ratio shows the existence of non-sink conditions with a subsequent lower dissolution rate. On the basis of solubility, sink conditions can be achieved using $0.1 \mathrm{~N} \mathrm{HCl}$ as dissolution medium. The rate of drug dissolution will be slowed by the limited solubility of the drug in that medium. Non-sink conditions is expected using purified water (with and without surfactant) due to the lower solubility-to-dose ratio $(<3)$.

\section{Selection of Discriminatory Dissolution Test Conditions}

Suitable dissolution test conditions were selected on the basis of a screening study conducted on orally disintegrating tablets of domperidone (10 mg) using USP Apparatus 2 (paddle). The dissolution rate was determined in different dissolution media $(0.1 \mathrm{~N} \mathrm{HCl}$, purified water, and purified water containing $0.5,1.0$, and $1.5 \%$ Tween 80), at different volumes ( 450 and $900 \mathrm{~mL}$ ), and at different stirring speeds ( 50 and $75 \mathrm{rpm}$ ).

ODTs of domperidone exhibited similar dissolution profiles at the two levels of paddle speed ( 50 and $75 \mathrm{rpm}$ ) irrespective of dissolution volume. The highest dissolution rate was observed with the officially recommended dissolution medium $(0.1 \mathrm{~N} \mathrm{HCl})$, irrespective of volume of dissolution medium and paddle speed due to higher solubility-to-dose ratio (29.86). There was no difference in percentage of drug released at 50 and $75 \mathrm{rpm}$ in different volumes ( 450 and $900 \mathrm{~mL}$ ) of the $0.1 \mathrm{~N} \mathrm{HCl}$ because of its high solubility. On the other hand, up to $10 \%$ drug release was observed in phosphate buffer $(\mathrm{pH}$ 6.8) due to poor solubility of domperidone.

Drug release in purified water was very slow; $49.18 \%$ of drug released within $60 \mathrm{~min}$ at higher volume $(900$ $\mathrm{mL}$ ) and lower paddle speed (50 rpm). A decrease in volume further reduced the dissolution rate without any significant effect of the paddle speed, as shown in Figure 1. Domperidone is practically insoluble in water with a very low solubility-to-dose ratio $(0.85)$ leading to its incomplete dissolution rate. The use of distilled water as dissolution medium is usually not recommended due to its limited buffering capacity.

Inclusion of Tween 80 into purified water led to a concentration-dependent increase in dissolution rate. Greater than $100 \%$ of drug was released from an ODT within $60 \mathrm{~min}$ in $900 \mathrm{~mL}$ of dissolution medium consisting

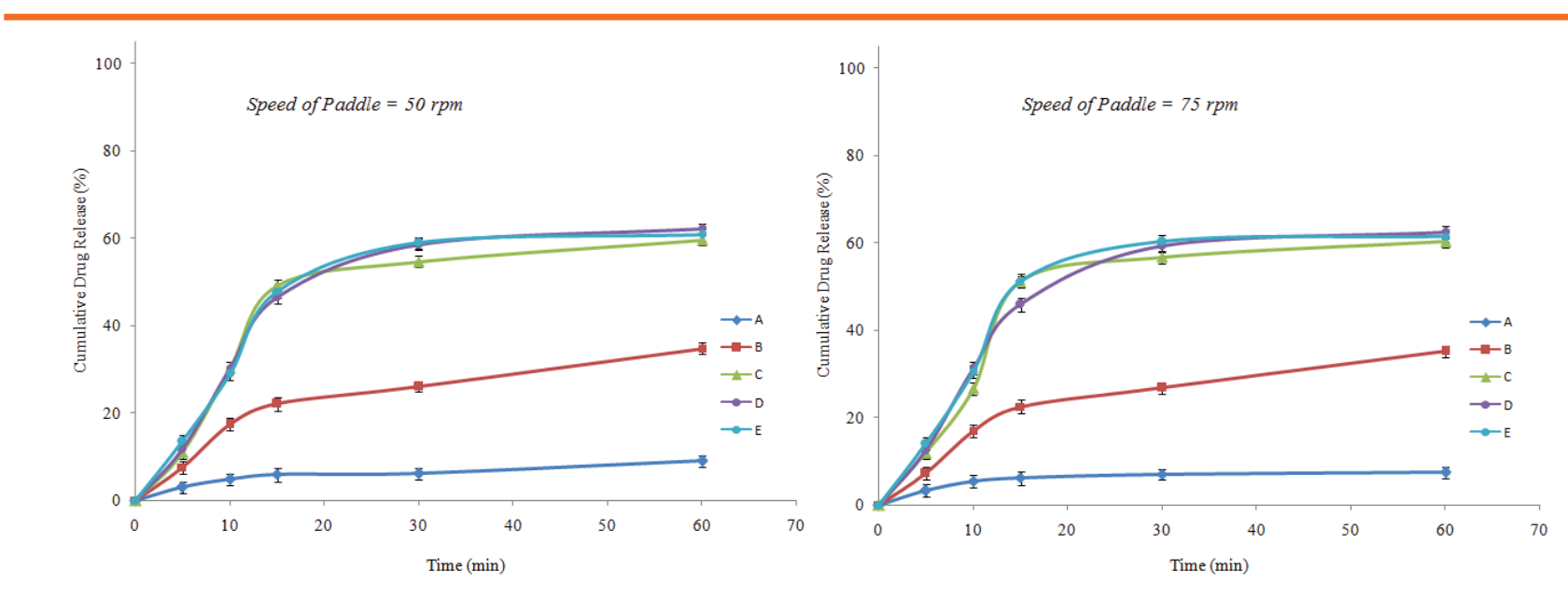

Figure 1. Release profiles of domperidone from ODTs determined at different paddle speeds (50 and $75 \mathrm{rpm})$ in $450 \mathrm{~mL}$ of medium: (A) pH 6.8 phosphate buffer; (B) purified water; (C) purified water $+0.5 \%$ Tween $80 ;(D)$ purified water $+1.0 \%$ Tween $80 ;(E)$ purified water $+1.5 \%$ Tween 80 . 

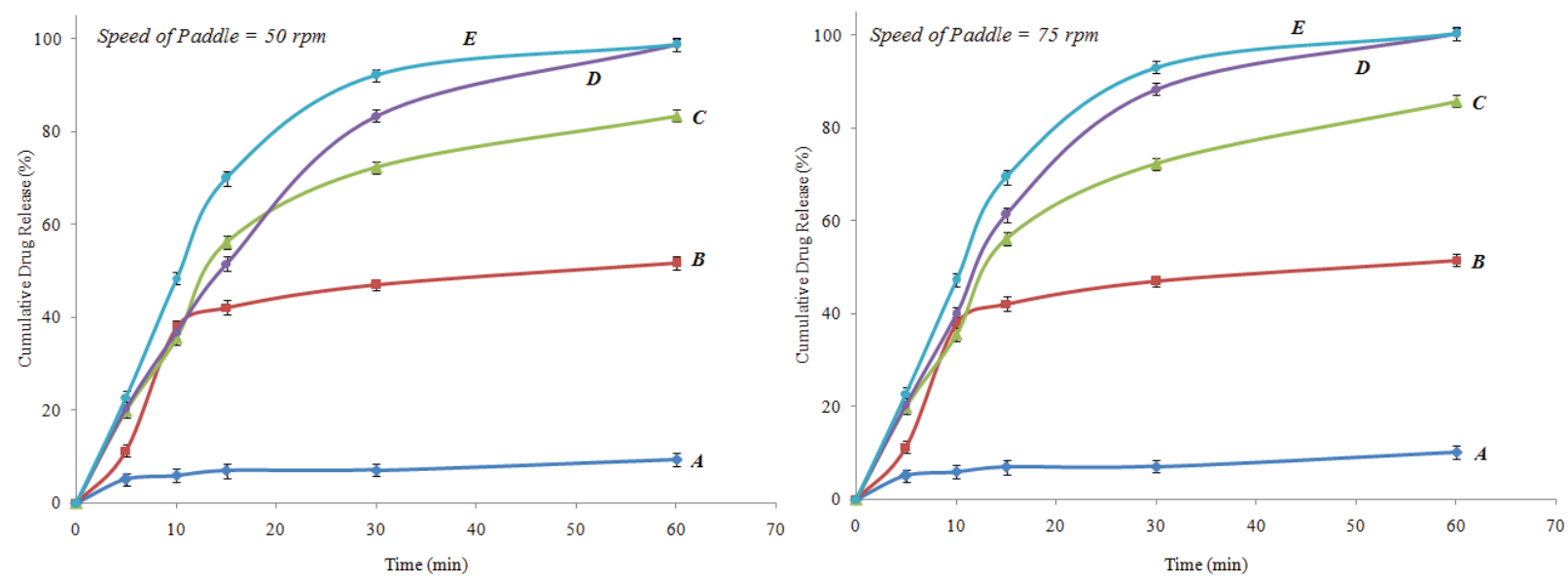

Figure 2. Release profiles of domperidone from ODTs determined at paddle speeds of 50 and $75 \mathrm{rpm}$ in $900 \mathrm{~mL}$ of dissolution media : (A) pH 6.8 phosphate buffer; (B) purified water; (C) purified water $+0.5 \%$ Tween $80 ;(D)$ purified water $+1.0 \%$ Tween $80 ;(E)$ purified water $+1.5 \%$ Tween 80 .

of purified water and Tween $80(1 \% \mathrm{w} / \mathrm{v})$ at a paddle speed of $50 \mathrm{rpm}$. Moreover, the dissolution rate was relatively slower and consistent, irrespective the paddle speed (Figure 2). A further increase in the concentration of Tween $80(1.5 \% \mathrm{w} / \mathrm{v})$ did not increase the dissolution rate significantly.

The use of surfactants in the dissolution medium for sparingly soluble drugs is physiologically relevant and well-documented (33). A dissolution medium containing surfactant can better simulate the environment of the gastrointestinal tract than a medium containing organic solvents or other nonphysiological substances. The addition of a small amount of surfactant at less than its critical micelle concentration is often sufficient to solubilize certain drug products. In those cases where a higher concentration of surfactant leads to faster dissolution, any potential correlation with in vivo performance is lost (34); therefore, a low concentration of surfactant is a modifier of choice. Furthermore, the

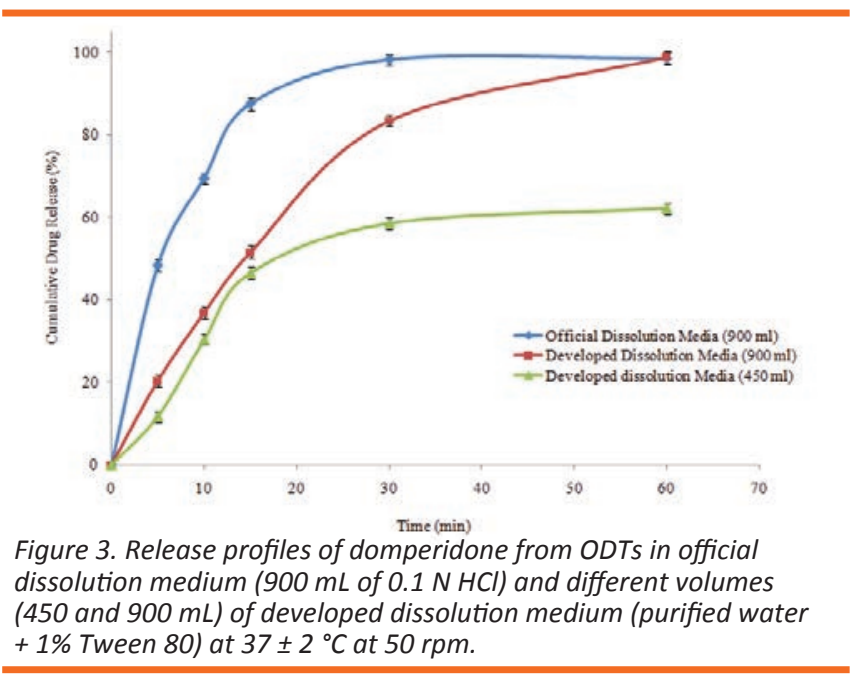

volume of dissolution medium exhibited a significant effect on the dissolution rate of domperidone, while the effect of paddle speed was negligible.

Use of the slowest calibrated paddle speed $(50 \mathrm{rpm})$ and a combination of water and Tween $80(1 \% \mathrm{w} / \mathrm{v})$ resulted in a method with a better drug release profile of domperidone from ODTs, with a higher discriminating power (33). Hence USP Apparatus 2 at $50 \mathrm{rpm}$ with 900 $\mathrm{mL}$ of purified water containing $1 \%$ Tween 80 was chosen as the conditions for the dissolution method. The drug release profile obtained in the developed dissolution test was satisfactory, as shown in Figure 3.

\section{Confirmation of Discriminative Dissolution Test Conditions}

For confirmation of discriminative dissolution test conditions, ODTs of domperidone containing APIs of different particle sizes were prepared, and the in vitro release was determined in the selected dissolution medium (purified water $+1 \%$ Tween 80 ) at $50 \mathrm{rpm}$. Different dissolution profiles were obtained for ODTs of varying nature (Figure 4). The similarity factor $\left(f_{2}=43\right)$ and dissimilarity factor $\left(f_{1}=68\right)$ were calculated for both the profiles, which further confirmed dissimilarity.

Based these results, this dissolution test method is considered discriminative because it differentiates between products having differences in pharmaceutical attributes (variation in particle size of the API). From the study of drug release profiles, it is possible to establish dissolution test parameters that can be used as an alternative to the official dissolution test for domperidone tablets. The use of $900 \mathrm{~mL}$ of purified water containing Tween $80(1 \% \mathrm{w} / \mathrm{v})$ at $37{ }^{\circ} \mathrm{C}$ with a stirring rate of $50 \mathrm{rpm}$ provided discriminative results for orally disintegrating domperidone tablets. 

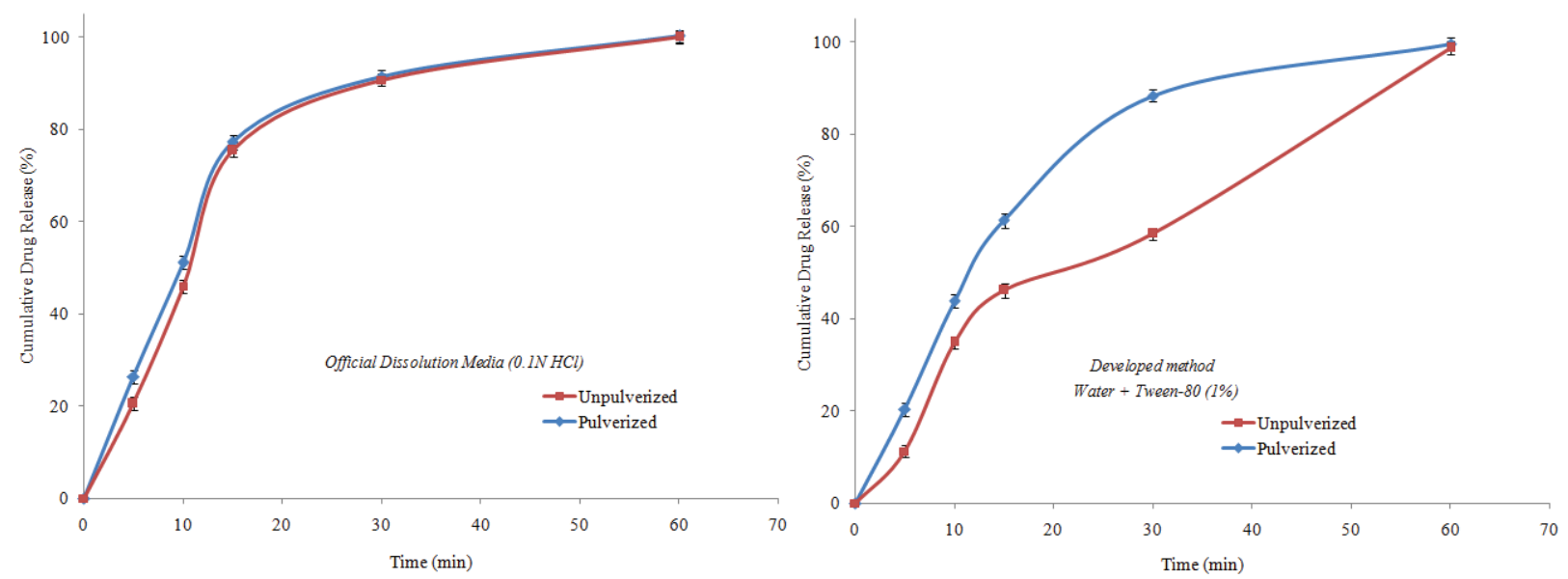

Figure 4. Release profiles of domperidone from ODTs containing pulverized and un-pulverized API, determined in official dissolution medium $(0.1 \mathrm{~N} \mathrm{HCl})$ and developed medium (purified water $+1 \%$ Tween 80) at constant volume $(900 \mathrm{~mL}$ ) and paddle speed of $50 \mathrm{rpm}$.

Validation of Developed Method of Dissolution Testing The dissolution test method for domperidone ODTs was validated according to the standard (ICH) guidelines (26).

\section{Specificity}

Specificity of the method was estimated on the basis of chromatographic response of the blank dissolution medium and dissolution medium containing different concentrations of domperidone. The chromatogram of dissolution medium was free of any interfering peak, while media with different concentrations of domperidone exhibited peaks with concentration-dependant areas and constant retention times. Peak purity was further confirmed using the peak purity tool provided in the HPLC software (TotalChrom workstation, version 6.3.1; Perkin Elmer, Billerica, MA, USA). The value obtained for peak purity was $\approx 1$, indicating better purity of the peak.

\section{Accuracy}

Accuracy of the method was evaluated on the basis of percent recovery. Percent recovery from 95.0 to $105.0 \%$ is recommended for the accuracy test. The mean recovery for domperidone was in the range of $99.5-102.9 \%$, as shown in Table 2, indicating that the dissolution method is accurate.

\section{Precision}

Results for the intraday and interday precision are summarized in Table 2. The RSD value is less than $1 \%$ and shows that the dissolution method has good precision.

\section{Stability}

The stability of domperidone in the dissolution medium (purified water + Tween 80) was evaluated using standards and samples. The drug content of the samples was within $98-102 \%$ (Table 3 ) of the initial value over the test period (7 days), and no degradation products were observed in any of the chromatograms, indicating stability of domperidone in the dissolution medium.

Table 2. Dissolution Method Validation Parameters

\begin{tabular}{|c|c|}
\hline Parameter & Result (Mean \pm SD; RSD) \\
\hline \multicolumn{2}{|l|}{ Accuracy } \\
\hline $8 \mathrm{mg}(80 \%)$ & $99.86 \pm 0.59 ; 0.59$ \\
\hline $10 \mathrm{mg}(100 \%)$ & $100.01 \pm 0.32 ; 0.32$ \\
\hline $12 \mathrm{mg}(120 \%)$ & $100.09 \pm 0.53 ; 0.53$ \\
\hline \multicolumn{2}{|l|}{ Precision } \\
\hline \multicolumn{2}{|l|}{ Repeatability } \\
\hline Vessel $1\left(\mathrm{~V}_{1}\right)$ & $99.92 \pm 0.41 ; 0.41$ \\
\hline Vessel $2\left(V_{2}\right)$ & $100.02 \pm 0.51 ; 0.51$ \\
\hline Vessel $3\left(V_{3}\right)$ & $100.10 \pm 0.32 ; 0.32$ \\
\hline Vessel $4\left(V_{4}\right)$ & $99.78 \pm 0.58 ; 0.58$ \\
\hline Vessel $5\left(V_{5}\right)$ & $100.90 \pm 0.62 ; 0.62$ \\
\hline Vessel $6\left(V_{6}\right)$ & $100.05 \pm 0.49 ; 0.49$ \\
\hline \multicolumn{2}{|c|}{ Intermediate precision } \\
\hline \multicolumn{2}{|c|}{ Intraday reproducibility } \\
\hline $08 \mathrm{hr}$ & $100.02 \pm 0.51 ; 0.51$ \\
\hline $16 \mathrm{hr}$ & $99.95 \pm 0.87 ; 0.87$ \\
\hline $24 \mathrm{hr}$ & $100.03 \pm 0.69 ; 0.69$ \\
\hline \multicolumn{2}{|c|}{ Interday reproducibility } \\
\hline Day 1 & $100.02 \pm 0.51 ; 0.51$ \\
\hline Day 2 & $99.81 \pm 0.70 ; 0.70$ \\
\hline Day 3 & $100.09 \pm 0.48 ; 0.48$ \\
\hline
\end{tabular}

Results are mean $\pm S . D ; R S D(n=3)$.

Dissolution medium: purified water + Tween $80(1 \%)$, temperature: $37 \pm 2{ }^{\circ} \mathrm{C}$, paddle speed: $50 \mathrm{rpm}$; medium volume: $900 \mathrm{~mL}$. 
Table 3. Percent Recovery (Stability) of Domperidone from Various Solvents (Methanol and Different Dissolution Media) after Storage at Different Conditions for Seven Days

\begin{tabular}{|c|c|c|c|}
\hline \multirow{2}{*}{$\begin{array}{c}\text { Composition of } \\
\text { Solvent }\end{array}$} & $\begin{array}{c}\text { Ambient } \\
\text { Temperature }\end{array}$ & $\begin{array}{c}\text { Refrigerator } \\
\text { Temperature }\end{array}$ & $\begin{array}{c}\text { Elevated } \\
\text { Temperature }\end{array}$ \\
\cline { 2 - 4 } & $99.78 \pm 0.53$ & $99.9 \pm 0.43$ & $99.86 \pm 0.37$ \\
\hline Stock Solution & $100.09 \pm 0.61$ & $99.82 \pm 0.67$ & $99.63 \pm 0.60$ \\
\hline $\begin{array}{c}\text { Purified Water }+ \\
0.5 \% \text { Tween } 80\end{array}$ & $99.67 \pm 0.29$ & $99.69 \pm 0.28$ & $99.59 \pm 0.72$ \\
\hline $\begin{array}{c}\text { Purified Water }+1 \% \\
\text { Tween } 80\end{array}$ & $99.63 \pm 0.51$ & $99.78 \pm 0.79$ & $99.83 \pm 0.58$ \\
\hline $\begin{array}{c}\text { Purified Water }+ \\
1.5 \% \text { Tween } 80\end{array}$ & \multicolumn{2}{|c|}{} \\
\hline
\end{tabular}

\section{CONCLUSION}

A robust, discriminating dissolution method for domperidone ODTs was developed and validated according to $\mathrm{ICH}$ guidelines. An initial study was conducted by evaluating the dissolution profiles of ODTs using different dissolution media at varying volumes (450 and $900 \mathrm{~mL}$ ) and stirring rates ( 50 and $75 \mathrm{rpm}$ ). The use of $900 \mathrm{~mL}$ of purified water containing $1 \%$ Tween 80 as the dissolution medium at $37 \pm 0.5{ }^{\circ} \mathrm{C}$ and 50 rpm produced satisfactory results. Dissolution testing of ODTs containing APIs with different particle sizes resulted in different dissolution profiles, confirming the discriminatory nature of the method. The comparison of the obtained dissolution profiles was realized by the factors $f_{1}$ and $f_{2}$ and showed significant differences. The developed dissolution method will be helpful in formulation development of ODTs and assessment of quality and performance of different batches.

\section{ACKNOWLEDGMENT}

We are thankful to the management of Medicraft Pharmaceutical Ltd. Peshawar, Pakistan, for provision of domperidone.

\section{CONFLICT OF INTEREST}

The author claims no conflict of interest.

\section{REFERENCES}

1. Pillay, V.; Fassihi, R. Evaluation and comparison of dissolution data derived from different modified release dosage forms: an alternative method. J. Controlled Release 1998, 55 (1), 45-55. DOI: 10.1016/S0168-3659(98)00022-4.

2. He, Z.; Zhong, D.; Chen, X.; Liu, X.; Tang, X.; Zhao, L. Development of a dissolution medium for nimodipine tablets based on bioavailability evaluation. Eur. J. Pharm. Sci. 2004, 21 (4), 487491. DOI: 10.1016/j.ejps.2003.11.009.

3. Buch, P.; Langguth, P.; Kataoka, M.; Yamashita, S. IVIVC in oral absorption for fenofibrate immediate release tablets using a dissolution/permeation system. J. Pharm. Sci. 2009, 98 (6), 2001-2009. DOI: 10.1002/jps.21576.

4. Raju, V.; Murthy, K. V. R. Development and Validation of New Discriminative Dissolution Method for Carvedilol Tablets. Indian J. Pharm. Sci. 2011, 73 (5), 527-536. DOI: 10.4103/0250474x.99000.

5. Yuksei, N.; Kanik, A. E.; Baykara, T. Comparison of in vitro dissolution profiles by ANOVA-based, model-dependent and -independent methods. Int. J. Pharm. 2000, 209 (1-2), 57-67. DOI: 10.1016/S0378-5173(00)00554-8.

6. Bonfilio, R.; Pires, S. A.; Ferreira, L. M. B.; deAlmeida, A. E.; Doriguetto, A. C.; deAraújo, M. B.; Salgado, H. R. N. A Discriminating Dissolution Method for Glimepiride Polymorphs. J. Pharm. Sci. 2012, 101 (2), 794-804. DOI: 10.1002/jps.22799.

7. Lima, A. A. N.; Sobrinho, J. L. S.; Corrêa.; Pedro, J. R. Alternative technologies to improve solubility of poorly water soluble drugs. Lat. Am. J. Pharm. 2008, 27 (5), 789-797.

8. Corrêa, E. M.; Vila, M. M. D. C.; Junior, J. M. O.; Zaparoli, R. E.; Granato, M. M. ; Goes, A. L.; Moraes, L. C.; Paula, F. C.; Chaud, M. V. Assessment of Solubility and Intestinal Absorption In Vitro of Praziquantel in Solid Dispersions of Polyethylene Glycol 6000. Lat. Am. J. Pharm. 2011, 30 (10), 1910-1915.

9. Heo, M.-Y.; Piao, Z.-Z.; Kim, T.-W.; Cao, Q.-R.; Kim, A.; Lee, B.-J. Effect of solubilizing and microemulsifying excipients in polyethylene glycol 6000 solid dispersion on enhanced dissolution and bioavailability of ketoconazole. Arch. Pharm. Res. 2005, 28 (5), 604-611. DOI: 10.1007/bf02977766.

10. Ashokraj, Y.; Daroi, A.; Gupta, G.; Khanolkar, A.; Kulkarni, A.; Laud, S.; Pokale, M.; Shedge, S.; Date, P. Discriminatory Dissolution Method Development and Validation of Etoricoxib Tablets. Dissolution Technol. 2016, 30-34. DOI: 10.14227/DT230216P30.

11. Singla, N.; Gupta, G. D.; Kohli, K.; Singla, A. K. A Discriminatory and Biorelevant Dissolution Test Method for Simvastatin Drug Products. Dissolution Technol. 2009, 16 (4), 11-13. DOI: 10.14227/DT160409P11.

12. Martin, G. P.; Gray, V. A. Validation of Dissolution Methods. J. Validation Technol. 2011, 28-31.

13. European Pharmacopoeia, 6th ed.; European Directorate for the Quality of Medicines \& Healthcare, Council of Europe: Strasbourg, France, 2008.

14. Abdelbary, G.; Eouani, C.; Prinderre, P.; Joachim, J.; Reynier, J.; Piccerelle, P. Determination of the in vitro disintegration profile of rapidly disintegrating tablets and correlation with oral disintegration. Int. J. Pharm. 2005, 292 (1-2), 29-41. DOI: 10.1016/j.ijpharm.2004.08.019.

15. Aboutaleb, A. E.; Abdel-Rahman, S. I.; Ahmed, M. O.; Younis, M. A. Improvement of Domperidone Solubility and Dissolution Rate by Dispersion in Various Hydrophilic Carriers. J. Appl. Pharm. Sci. 2016, 6 (7), 133-139. DOI: 10.7324/japs.2016.60720.

16. Dobetti, L. Fast-Melting Tablets: Developments and Technologies. Pharm. Technol. 2001, 25 (1), 44-55.

17. Sugimoto, M.; Narisawa, S.; Matsubara, K.; Yoshino, H.; Nakano, 
M.; Handa, T. Development of manufacturing method for rapidly disintegrating oral tablets using the crystalline transition of amorphous sucrose. Int. J. Pharm. 2006, 320 (1-2), 71-78. DOI: 10.1016/j.ijpharm.2006.04.004.

18. Gohel, M.; Patel, M.; Amin, A.; Agrawal, R.; Dave, R.; Bariya, $\mathrm{N}$. Formulation design and optimization of mouth dissolve tablets of nimesulide using vacuum drying technique. AAPS PharmSciTech 2004, 5 (3), 10-15. DOI: 10.1208/pt050336.

19. Okuda, Y.; Irisawa, Y.; Okimoto, K.; Osawa, T.; Yamashita, S. A new formulation for orally disintegrating tablets using a suspension spray-coating method. Int. J. Pharm. 2009, 382 (1-2), 80-87. DOI: 10.1016/j.ijpharm.2009.08.010.

20. Khan, A. Abasyn University, Peshawar, Pakistan. Unpublished work, 2016.

21. Khan, A.; Iqbal, Z.; Rehman, Z.; Nasir, F.; Khan, A.; Ismail, M.; Roohullah; Mohammad, A. Application of SeDeM Expert system in formulation development of effervescent tablets by direct compression. Saudi Pharm. J. 2014, 22 (5), 433-444. DOI: 10.1016/j.jsps.2013.07.002.

22. Silvers, D.; Kipnes, M.; Broadstone, V.; Patterson, D.; Quigley, E. M. M.; McCallum, R.; Kline Leidy, N.; Farup, C.; Liu, Y.; Joslyn, A. Domperidone in the management of symptoms of diabetic gastroparesis: Efficacy, tolerability and quality-of-life outcomes in a multicenter controlled trial. Clin. Ther. 1998, 20 (3), 438453. DOI: 10.1016/s0149-2918(98)80054-4.

23. Khan, A.; Iqbal, Z.; Khan, A.; Mughal, M. A.; Khan, A.; Ullah, Z.; Khan, I. Modulation of $\mathrm{pH}-$ Independent Release of a Class II Drug (Domperidone) from a Polymeric Matrix Using Acidic Excipients. Dissolution Technol. 2016, 23 (1), 32-40. DOI: 10.14227/DT230116P32.

24. Khoo, S.-M.; Humberstone, A. J.; Porter, C. J. H.; Edwards, G. A.; Charman, W. N. Formulation design and bioavailability assessment of lipidic self-emulsifying formulations of halofantrine. Int. J. Pharm. 1998, 167 (1-2), 155-164. DOI: 10.1016/s0378-5173(98)00054-4.

25. Khan, A.; Iqbal, Z.; Khadra, I.; Ahmad, L.; Khan, A.; Khan, M. I.; Ullah, Z.; Khan, I. Simultaneous determination of domperidone and Itopride in pharmaceuticals and human plasma using RPHPLC/UV detection: Method development, validation and application of the method in in-vivo evaluation of fast dispersible tablets. J. Pharm. Biomed. Anal. 2016, 121, 6-12. DOI: 10.1016/j. jpba.2015.12.036.

26. Note for Guidance on Validation of Analytical Procedures: Text and Methodology, CPMP/ICH/381/95; Committee for Medicinal Products for Human Use (CHMP), European Medicines Agency: London, 2009.

27. Costa, P.; Lobo, J. M. S. Modeling and comparison of dissolution profiles. Eur. J. Pharm. Sci. 2001, 13 (2), 123-133. DOI: 10.1016/ S0928-0987(01)00095-1.

28. Mamani, P. L.; Ruiz-Caro, R.; Veiga, M. D. Matrix Tablets: The Effect of Hydroxypropyl Methylcellulose/Anhydrous Dibasic Calcium Phosphate Ratio on the Release Rate of a Water-Soluble Drug Through the Gastrointestinal Tract I. In Vitro Tests. AAPS PharmSciTech 2012, 13 (4), 1073-1083. DOI: 10.1208/s12249012-9829-9.

29. Javadzadeh, Y.; Jafari-Navimipour, B.; Nokhodchi, A. Liquisolid technique for dissolution rate enhancement of a high dose water-insoluble drug (carbamazepine). Int. J. Pharm. 2007, 341 (1-2), 26-34. DOI: 10.1016/j.ijpharm.2007.03.034.

30. The British Pharmacopoeia; The Stationery Office: London, 2012.

31. Nagarsenker, M. S.; Garad, S. D.; Ramprakash, G. Design, optimization and evaluation of domperidone coevaporates, J. Controlled Release 2000, 63 (1-2), 31-39. DOI: 10.1016/S01683659(99)00177-7.

32. Qureshi, S. A. Developing Discriminatory Drug Dissolution Tests and Profiles: Some Thoughts for Consideration on the Concept and Its Interpretation. Dissolution Technol. 2006, 13 (4), 18-23. DOI: 10.14227/DT130406P18.

33. Brown, C. K.; Chokshi, H. P.; Nickerson, B.; Reed, R. A.; Rohrs, B. R.; Shah, P. A. Acceptable Analytical Practices for Dissolution Testing of Poorly Soluble Compounds. Pharm. Technol. 2004, 28 (12), 56-65.

34. Cristofoletti, R.; Dressman, J. B. Dissolution Methods to Increasing Discriminatory Power of In Vitro Dissolution Testing for Ibuprofen Free Acid and Its Salts. J. Pharm. Sci. 2016, 106 (1), 92-99. DOI: 10.1016/j.xphs.2016.06.001. 